\title{
CATHARE Assessment of Natural Circulation in the PKL Test Facility during Asymmetric Cooldown Transients
}

\author{
Anis Bousbia Salah and Jacques Vlassenbroeck \\ Bel V (Subsidiary of the Belgian Federal Agency for Nuclear Control), Walcourtstraat 148, 1070 Brussels, Belgium \\ Correspondence should be addressed to Anis Bousbia Salah, anis.bousbiasalah@belv.be
}

Received 1 March 2011; Accepted 25 May 2011

Academic Editor: Alessandro Del Nevo

Copyright ( 2012 A. Bousbia Salah and J. Vlassenbroeck. This is an open access article distributed under the Creative Commons Attribution License, which permits unrestricted use, distribution, and reproduction in any medium, provided the original work is properly cited.

\begin{abstract}
Results of the CATHARE code calculations related to asymmetric cooldown tests in the PKL facility are presented. The test under consideration is the G2.1 experiment performed within the OECD/NEA PKL-2 project. It consists of carrying out a cooldown under natural circulation conditions in presence of two (out of four) emptied Steam Generators (SGs) and isolated on their secondary sides. The main goal of the current study is to assess the impact of a chosen cooldown strategy upon the occurrence of a Natural Circulation Interruption (NCI) in the inactive (i.e., noncooling) loops. For this purpose, three G2.1 test runs were investigated. The calculation results emphasize, mainly, the effect of the cooldown strategy, and the conditions that could lead to the occurrence of the NCI phenomenon.
\end{abstract}

\section{Introduction}

After the reactor trip, several cooldown procedures can be followed in order to bring the primary side temperature and pressure to the Residual Heat Removal System (RHRS) operating conditions. For example, the primary cooldown can be carried out by a linear or stepwise temperature decrease, with a coincident or delayed depressurization. Generally, the Emergency Response Guidelines (ERG) impose a limit on the cooldown rate in order to prevent steam bubble formation under the reactor vessel head during the depressurization phase. Furthermore, Natural Circulation Interruption (NCI) has also to be avoided during the cooldown phase as pointed out by [1]. Indeed, the interruption of natural circulation in one or more inactive primary loops could stop the cooldown in these loops and lead to degradated states $[1,2]$.

Up to now, the NCI phenomenon has not yet been deeply investigated analytically and experimentally as well. The issue was addressed by the OECD/NEA PKL-2 project [3] in order to assess the impact of different cooldown strategies on the occurrence of the flow stagnation in the inactive loops where the corresponding SGs are emptied and isolated. Former studies, on the PKL facility, made by Dubiel and Mandl [4] showed that NCI could occur in the loop with isolated and filled SGs if a (stepwise) cooldown at $50^{\circ} \mathrm{C} / \mathrm{h}$, with a mean value around $10^{\circ} \mathrm{C} / \mathrm{h}$, is performed. Recently, Vlassenbroeck et al. [1] investigated the NCI in a typical 2-loop NPP using a thermal-hydraulic system code. The latter study emphasised the fact that a linear cooldown rate larger than $14^{\circ} \mathrm{C} / \mathrm{h}$ could lead to NCI.

In the current study, three experimental runs performed in the 4-loop PKL facility are considered. They concern three cooldown strategies under natural circulation conditions where 2 out of 4 SG are emptied and isolated on their secondary sides. The objective was to check if natural circulation is maintained in all loops at a continuous cooldown rate of $50^{\circ} \mathrm{C} / \mathrm{h}$ and if not, whether natural circulation can be maintained by a stepwise cooldown rate at $50^{\circ} \mathrm{C} / \mathrm{h}$.

The test simulation was carried out using the advanced thermal-hydraulic system code CATHARE 2/V2.5_1/mod8.1 developed by CEA, EDF, AREVA, and IRSN [5]. The current study allows drawing conclusions about the NCI occurrences under some specific conditions and also about the capabilities of the current computational tools in predicting the NCI phenomenon, to better understand the interaction between the key parameters expected during the transient. 


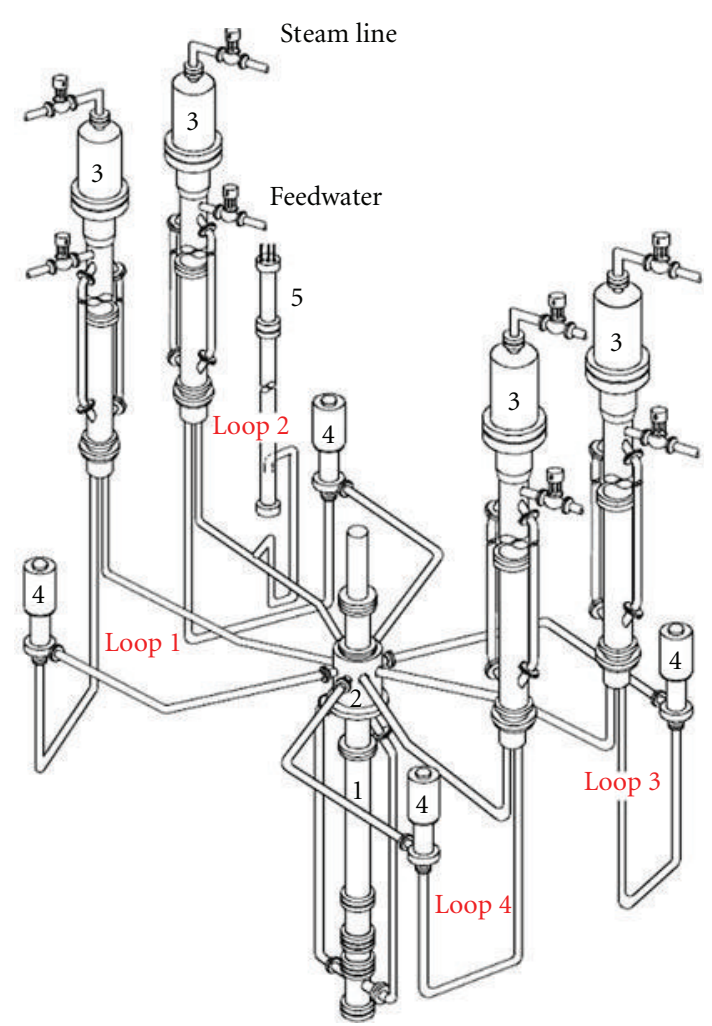

1 Reactor pressure vessel

2 Downcomer

3 Steam generator

4 Pump

5 Pressurizer

Figure 1: Layout of the PKL test facility [6].

\section{PKL Facility Description}

The PKL (Primaer KreisLauf) facility [6] has been built in order to perform experimental investigations related to different integral behaviour of a typical 4-loop 1300MW Siemens pressurized water reactor (PWR) plant under normal and accident conditions. The layout of the PKL facility (Figure 1) shows the primary side and the most significant components of the secondary side. The scaling ratios of the facility are $1: 1$ elevation ratio and $1: 145$ for the power, volumes, and the cross section areas. However, the maximum operating primary pressure is 45 bar.

The primary side is represented by 4 identical and symmetric loops arranged around the reactor pressure vessel. For each loop, a secondary side is associated, as well as all the significant interface and auxiliary systems.

\section{CATHARE Model for PKL}

The adopted CATHARE nodalization for the current study is a full $1 \mathrm{D}$ model. In total, the nodalization contains almost thousand of hydraulic nodes and heat structures distributed on the primary and the secondary side.

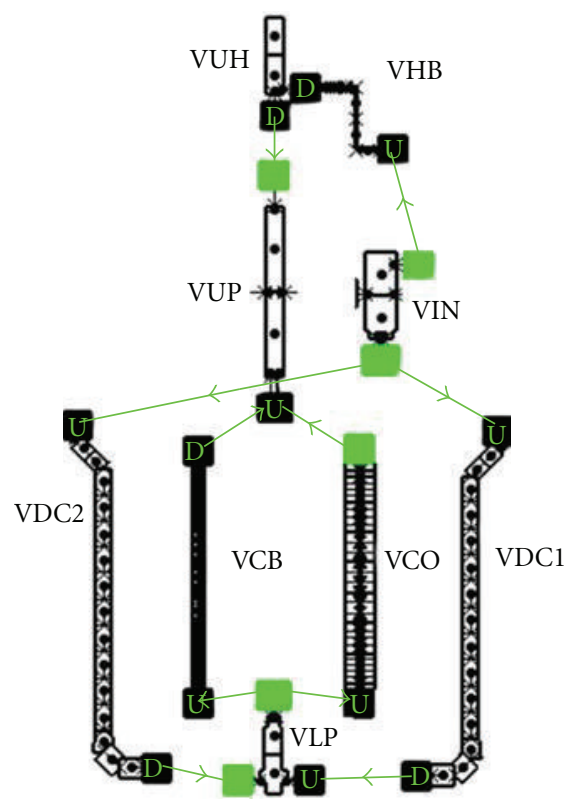

FIgure 2: CATHARE modelling of the PKL reactor vessel components.

3.1. PKL Reactor Vessel. The PKL vessel model as modelled by the CATHARE code is composed by the upper downcomer ring (VIN), the 2 downcomer pipes (VDC1 \& VDC2), the lower plenum (VLP), the heated core zone (VCO) and the core bypass (VCB) zone, the upper plenum (VUP), the upper head (VUH), and the upper head bypass (VHB). In Figure 2, the aforementioned components are shown, more details are provided in Table 1.

The downcomer consists of an upper downcomer ring where the flows coming from the different cooling loops are mixed up. The descending part of the downcomer consists of 2 pipes connecting the downcomer ring to the core lower plenum. The rod bundle consists of 314 uniformly disposed heated rods. The latter were lumped into one equivalent heating channel with a uniform axially distributed power. The CATHARE nodalization was chosen to fit the spacer's position. The geometry of the core upper plenum includes the connections to the 4 hot legs and the lower part of the upper head. The upper head is connected to the core upper plenum through 9 holes that simulate the guided tubes zone, and also to the upper part of the downcomer through 4 upper head bypass pipes.

3.2. Steam Generators (Primary Side). The SG zone is composed of an inlet zone, SG U-tubes, and an outlet zone. The total number of U-tubes in each SG is 28, distributed in 7 elevations having 4 tubes each (see Figure 3(a)). In the CATHARE model, for each elevation, the 4 tubes are lumped into one representative tube as shown in Figure 3(b). Each lumped tube is divided into 36 nodes in order to get a detailed representation of the heat transfer between the primary and secondary side. 


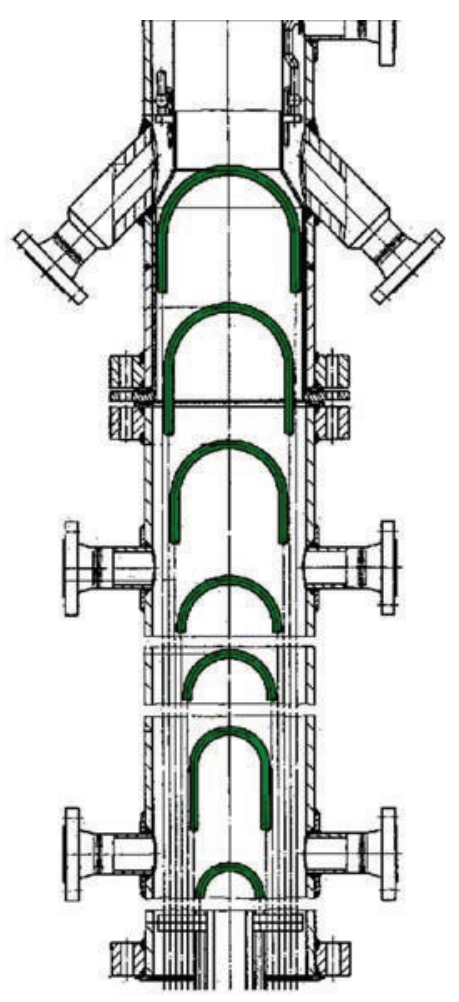

(a)

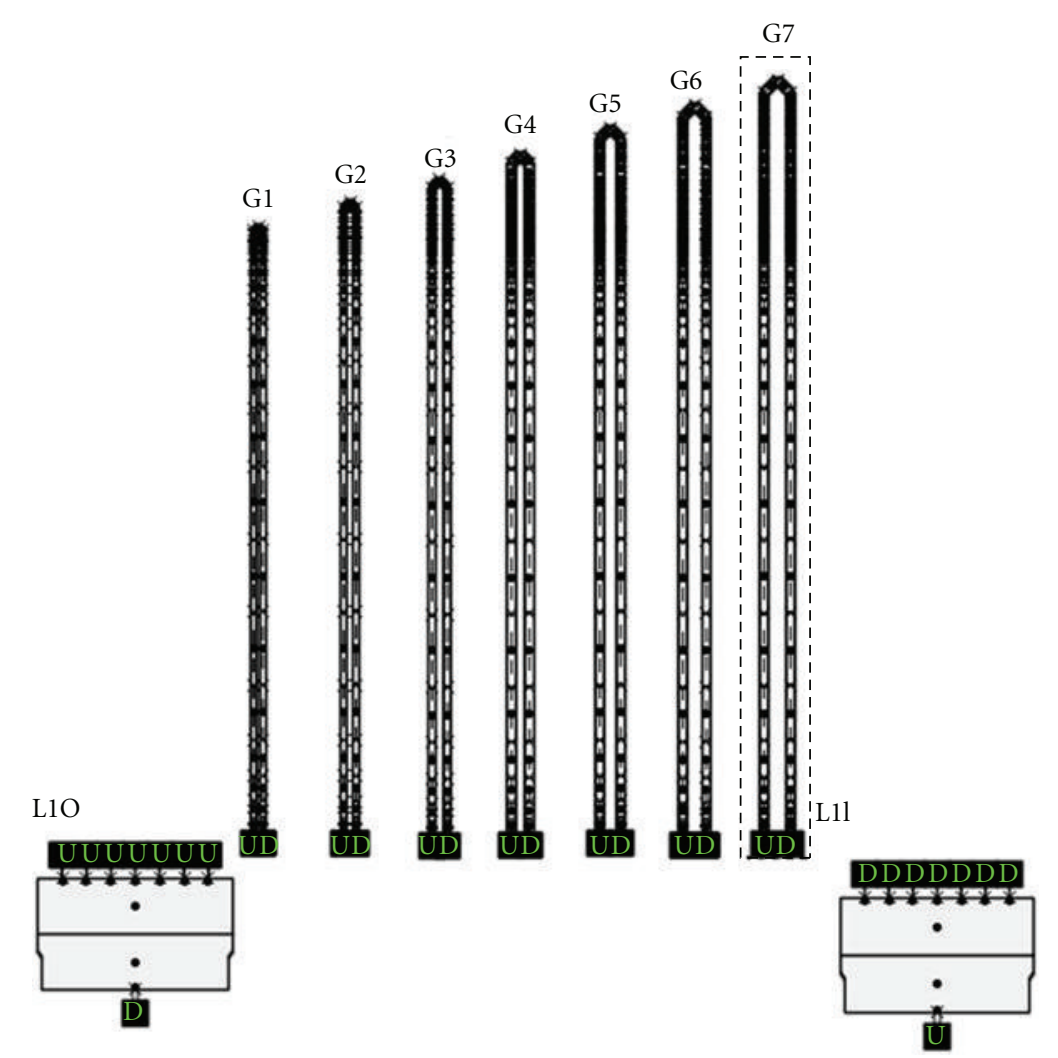

(b)

FIgURe 3: (a) The 7 U-tubes elevation geometry [6]. (b) U-tubes CATHARE model for the PKL configuration.

TABLE 1: Main components of the PKL reactor vessel.

\begin{tabular}{lcc}
\hline Component & CATHARE component & CATHARE element \\
\hline Lower plenum & VLP & VOLUME \\
Core bundle & VCO & AXIAL \\
Core bypass & VCB & AXIAL \\
Core upper plenum & VUP & VOLUME \\
Vessel upper head & VUH & VOLUME \\
Upper downcomer & VIN & VOLUME \\
Downcomer pipes & VDC1, VDC2 & AXIAL \\
Upper head bypass & VHB & AXIAL \\
\hline
\end{tabular}

3.3. Secondary Circuit Description and Modelling. The main components of the secondary circuit are summarized in Table 2. The CATHARE model of the secondary circuit is shown in Figure 4, in which the upper annular downcomer of the steam generator is represented by a VOLUME component. The latter is connected to the feedwater line, the two downcomer pipes, and the recirculation line (the carryunder of the steam separator of the SG). The downcomer is represented by one AXIAL component that lumps the 2 real pipes. The riser nodalization is chosen to cope with the primary side nodalization of the U-tubes in order to satisfy the CATHARE code rules concerning the heat exchange between the primary and secondary sides. The steam dome volume is modelled by the VOLUME component. The dryer or the separator option was not activated since in the real PKL configuration no special features exist for the phase separation.

3.4. Nodalization Assessment. The single-phase pressure losses of the PKL facility correspond to a large extent to the values encountered in a PWR. Under steady-state conditions, the pressure drop across the primary side was checked against measured data provided in [7], taking into account the butterfly valve (located downstream of each primary coolant pump) pressure drops that simulate the frictions of the locked rotor of the primary pumps. On the other hand, the heat losses of the main primary components were also tuned in the CATHARE model in order to match the measured heat 
TABLE 2: Main components of the PKL secondary side.

\begin{tabular}{lcc}
\hline Component & CATHARE component & CATHARE element \\
\hline Feed water line & FWn* & Axial \\
Annular downcomer & SnDW* & Volume \\
Downcomer pipes & DCnP* & Axial \\
Lower plenum & SnLP* & Volume \\
Riser & SnU $^{*}$ & Axial \\
Steam generator & $\mathrm{SnD}^{*}$ & Volume \\
Steam lines & $\mathrm{SLn}^{*}$ & Axial \\
\hline
\end{tabular}

${ }^{*} n$ is the loop number 1 to 4 .

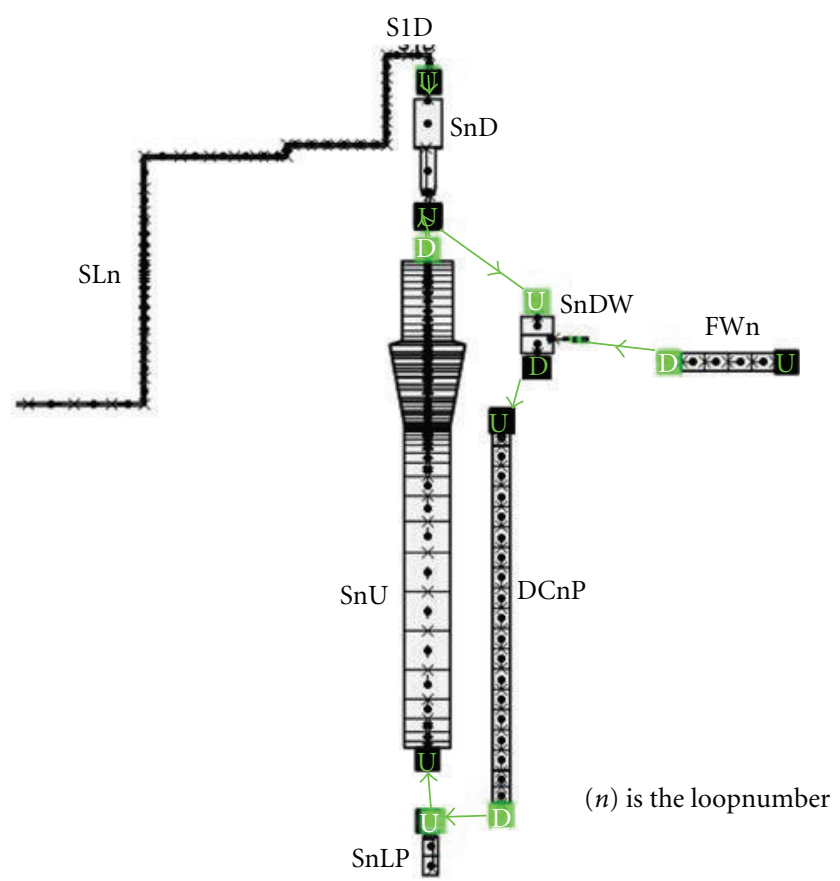

FIgURE 4: PKL secondary side view of the steam generator.

losses as documented in [8]. It should also be mentioned that some unknown cross section of some loop components were tuned in order to match the measured volumes as reported in [9].

The assessment of the nodalization is therefore carried out through a comparative study between the measured and calculated steady-state PKL operating conditions. This study is detailed in the following sections, and the main key parameters are outlined in Tables 6 and 7.

\section{G2.1 Test Description}

The PKL-2 G2.1 test consists of 3 runs in which 3 different cooldown procedures are followed. They concern three cooldown strategies under natural circulation conditions where 2 out of 4 SG are emptied and isolated on their secondary sides. The objective is to check if natural circulation is maintained in all loops at a continuous cooldown rate of $50^{\circ} \mathrm{C} / \mathrm{h}$ and if not, whether natural circulation can be maintained by a stepwise cooldown rate at $50^{\circ} \mathrm{C} / \mathrm{h}$.

In Run-1 and Run-2, a continuous cooldown with different way of decreasing the primary pressure is carried out, while for Run-3 a stepwise cooldown procedure is performed.

4.1. NCI Phenomenon. NCI can occur under single- or twophase flows due to several initiating events. Under two-phase flow, NCI can result from a loss of primary mass inventory as in the case of a small SBLOCA, or when a steam bubble is formed in the SG U-tubes.

On the other hand, during single-phase flow, NCI can occur progressively as the heat sink, in a loop, is gradually lost. The process is generally slow and can be described by the following single-phase momentum static governing set (1) under natural circulation conditions and negligible acceleration losses:

$$
\begin{gathered}
\oint_{\text {Vessel }} \rho g d z+\oint_{\mathrm{SG}(n)} \rho g d z+\oint_{\text {Hotleg-Coldleg }(n)} \rho g d z \\
=\Delta P_{f-\text { Vessel }}+\Delta P_{f-\operatorname{Loop}(n)}
\end{gathered}
$$

with $n=1,2,3,4$.

Indeed, when the heat sink is lost in loop 1 for instance, the second term of the left-hand side of (1) becomes null. Therefore, the flow in the inactive loop will decrease gradually and may stop when the driving force in the reactor pressure vessel minus the friction in the vessel are counterbalanced by the driving force in the inactive loop

$$
\oint_{\text {Hotleg-Coldleg }(1)} \rho g d z \approx \oint_{\text {Vessel }} \rho g d z-\Delta P_{f-\text { Vessel. }}
$$

4.2. Conditioning Phase. During the G2.1 test, the rod bundle power was fixed at $642 \mathrm{~kW}$ in which $100 \mathrm{~kW}$ was added to compensate the heat losses in the loops. This power level corresponds to a scaled decay heat power of $1.7 \%$.

The initial conditions of each of the individual test runs were adjusted through the so-called conditioning phases during which the secondary sides of SG-1 and SG-3 were emptied and isolated afterwards. The main test phase starts when the temperature level of the secondary side of the isolated SGs reaches the primary side temperature. 
TABLE 3: Main events for PKL2 G2.1 Run-1.

\begin{tabular}{ll}
\hline Time $[\mathrm{s}]$ & Measures/Events \\
\hline 0 & Start of Run-1 \\
360 & End of heat-up phase, Start of continuous cooldown at $50^{\circ}$ C/h by SG-2 and SG-4 \\
535 & PRZ heater switched off \\
2820 & Spraying in PRZ by volume control system switched on (Subcooling at core outlet maintained) \\
5300 & Flow stagnation in loop-1 \\
6770 & Flow stagnation in loop-3 \\
8680 & End of Run-1 \\
\hline
\end{tabular}

TABLe 4: Main events for PKL2 G2.1 Run-2.

\begin{tabular}{ll}
\hline Time $[\mathrm{s}]$ & Measures/Events \\
\hline 0 & Start of Run-2. Continuous cooldown initiated: continuous cooldown at $50^{\circ} \mathrm{C} / \mathrm{h}$ by SG-2 and SG-4 \\
80 & PRZ heater switched off \\
2240 & Spraying in PRZ by volume control system switched on (positive subcooling in the SGU-tubes is maintained) \\
6140 & Flow stagnation in loop-1 \\
7310 & End of Run-2 \\
\hline
\end{tabular}

4.3. Test Phase. For Run-1, the test consists in carrying out a continuous cooldown at $50^{\circ} \mathrm{C} / \mathrm{h}$ and primary depressurization by spraying in the pressurizer. The pressure decrease is controlled in order to ensure a subcooled margin at the core outlet. The main events for Run-1 are outlined in Table 3. It should be mentioned here that only for Run-1 a heat-up phase of $360 \mathrm{~s}$ was performed.

For Run-2, the test consists in carrying out a continuous cooldown rate of $50^{\circ} \mathrm{C} / \mathrm{h}$ but with controlled primary depressurization that ensures subcooling in the apex of the SG U-tubes. The main events for Run-2 are outlined in Table 4.

And finally for Run-3, a stepwise cooldown, during which subcooling in the SG U-tubes is maintained, is performed. The primary temperature is decreased successively after a short stabilization time by $20^{\circ} \mathrm{C}, 30^{\circ} \mathrm{C}$, and $40^{\circ} \mathrm{C}$ following a cooldown rate of $50^{\circ} \mathrm{C} / \mathrm{h}$. The main events for Run-3 are outlined in Table 5.

\section{Calculation and Experimental Results}

The simulation of each run covers the conditioning and the test phases. The results at the end of the conditioning phase are summarized in Tables 6 and 7 for the primary and secondary side, respectively. On the whole, good agreement between the calculation and the experimental results is obtained. This constitutes a good qualitative indicator for the representativeness of the developed CATHARE model for PKL as well.

5.1. G2.1 Run-1. The first run starts with the isolation of the secondary side of the active SG-2 and SG-4 from the steam header. A heat-up period in the primary side follows during $360 \mathrm{~s}$ approximately. The cooldown through the discharge valves begins afterwards.

At the beginning of the cooldown phase, as illustrated in Figure 5, the calculated hot-leg temperature in the active

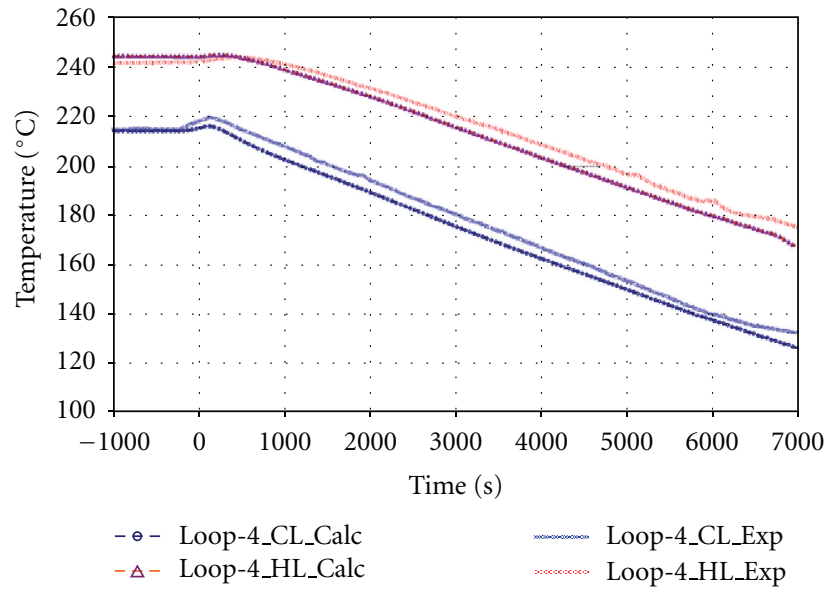

FIGURE 5: Run-1: Cold and hot leg temperature evolution in the active loops.

loops is overestimated by $2.0^{\circ} \mathrm{C}$. On the other hand, as illustrated in Figure 6, the flow in the active loops is underestimated by about $10 \%$, and overestimated by $20 \%$ in the inactive loops. This observation can be explained by the difference between the calculations and the measurements at the end of the conditioning phase. As can be seen in Figure 7, the heat sink in the experiment is almost lost, while it is not the case in the calculation results. This is more probably due to an underestimated calculated value of the secondary pressure. On the whole, at the beginning of the cooldown phase, the total primary flow agrees rather well with the experimental one.

Through the cooldown phase, the experimental and the calculated coolant temperature evolutions in loop- 2 and loop-4 follow well the linear $50^{\circ} \mathrm{C} / \mathrm{h}$ rate. This cooldown rate is obtained by controlling the atmospheric dump valve (ADV) opening on both steam lines, calculated as reported in Figure 8. The subsequent secondary pressure decreases are 
TABle 5: Main events for PKL2 G2.1 Run-3.

\begin{tabular}{ll}
\hline Time $[\mathrm{s}]$ & Measures/Events \\
\hline 0 & Start of Run-3. Cooldown step-1 initiated: $50^{\circ} \mathrm{C} / \mathrm{h}$ cooldown gradient by SG-2 and SG-4; temperature decrease by $20^{\circ} \mathrm{C}$ \\
90 & PRZ heater switched off \\
1460 & Cooldown step-1 finished \\
3270 & Cooldown step-2 initiated: $50^{\circ} \mathrm{C} / \mathrm{h}$ cooldown gradient by SG-2 and SG-4; temperature decrease by $30^{\circ} \mathrm{C}$ \\
5490 & Cooldown step-2 finished \\
7750 & Cooldown step-3 initiated: $50^{\circ} \mathrm{C} / \mathrm{h}$ cooldown gradient by SG-2 and SG-4; temperature decrease by $40^{\circ} \mathrm{C}$ \\
14870 & Cooldown step-3 finished \\
17520 & End of Run-3 \\
\hline
\end{tabular}

TABLE 6: Primary side steady-state results versus measurements for all runs.

\begin{tabular}{|c|c|c|c|c|c|c|}
\hline Primary circuit & EXP.RUN-1 & CALC.RUN-1 & EXP.RUN-2 & CALC.RUN-2 & EXP.RUN-3 & CALC.RUN-3 \\
\hline Pressure (bar) & 40 & 40 & 40 & 40 & 40 & 40 \\
\hline Bundle power $(\mathrm{kW})$ & 642 & 642 & 642 & 642 & 642 & 642 \\
\hline Core outlet Temp $\left({ }^{\circ} \mathrm{C}\right)$ & 243 & 244.0 & 241.5 & 244.5 & 241.1 & 244.5 \\
\hline Cold leg Temp $1-3\left({ }^{\circ} \mathrm{C}\right)$ & $239-243$ & 235 & 240.0 & 237.5 & 213.0 & 237.5 \\
\hline Cold leg Temp 2-4 $\left({ }^{\circ} \mathrm{C}\right)$ & 215. & 222.2 & 213.0 & 215.1 & 213.0 & 215.1 \\
\hline Subcooling at core outlet $\left({ }^{\circ} \mathrm{C}\right)$ & 5 & 6 & 6 & 7 & 7 & 7 \\
\hline Loop 2-4 mass flow rate $(\mathrm{kg} / \mathrm{s})$ & $1.35-1.45$ & 1.3 & $1.41-1.38$ & $1.38-1.39$ & 1.4 & $1.38-1.39$ \\
\hline Loop $1-3$ mass flow rate $(\mathrm{kg} / \mathrm{s})$ & $0.73-0.8$ & 1.0 & $0.72-0.77$ & $0.73-0.74$ & 0.75 & $0.73-0.74$ \\
\hline Pressurizer water level (m) & 4.0 & 4.15 & 4.1 & 4.15 & 4.1 & 4.15 \\
\hline
\end{tabular}

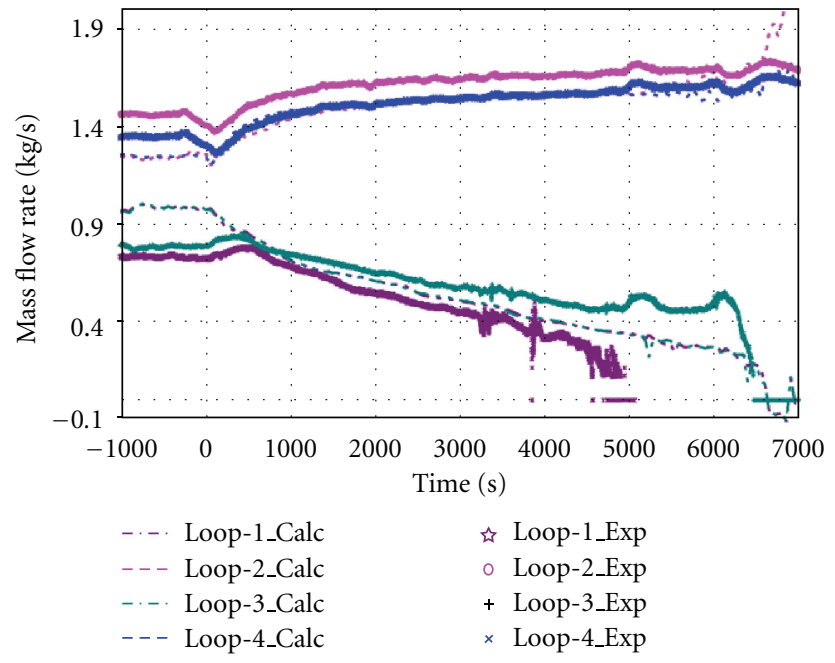

FIGURE 6: Run-1: Loops flow rate evolutions.

shown in Figure 9. The agreement between the calculations and the measurement is less good in this case.

In Figure 6, the flow rate evolutions in loop-2 and loop-4 agree well with the experimental trends but the agreement is less good in the inactive loops. In fact, differences exist between the measured flow rates in loop-1 and loop-3 and become more pronounced later on. Indeed, the flow interrupts first in loop-1, at around $5300 \mathrm{~s}$, and later in loop-3 after $1500 \mathrm{~s}$. This difference could be explained by the fact that loop-1 and loop-3 may have different pressure and heat losses. This is not the case in the CATHARE

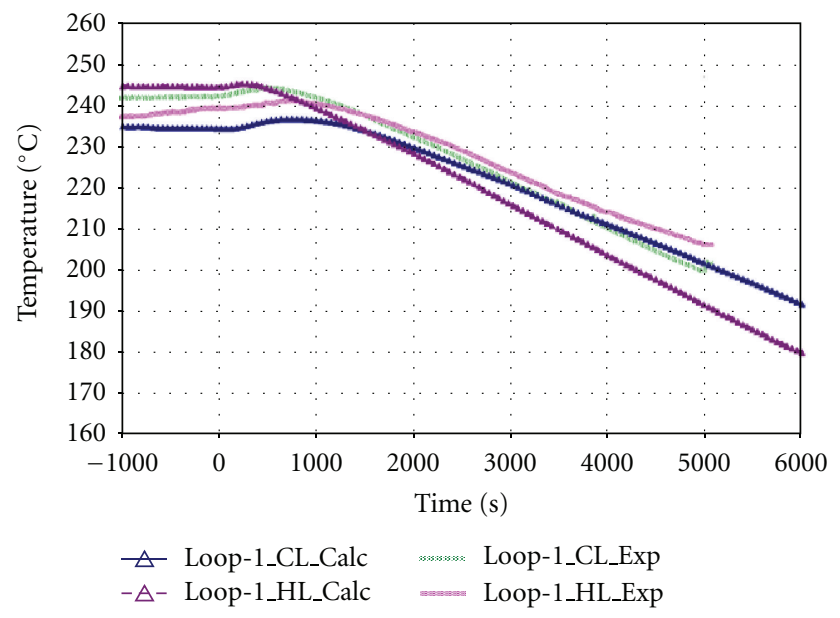

FIGURE 7: Run-1: Cold and hot leg temperature evolution in the active loops.

PKL model; the inactive loops are modelled identically and thus the calculated flow rates are the same, as well as the predicted flow interruption time occurrence (at about 7000 s). It should however be noted that the NCI in Run-1 is the consequence of steam formation in the U-tubes, due to continuous depressurization of the primary side.

According to the experimental and calculation results, the flow interruption process follows in some manner a chaotic trend. It does not start in the longest tube and end in the shortest one, as it could be expected. As can be seen in Figure 10(a), the flow for loop-1 is first interrupted in 
TABLE 7: Secondary side steady-state results versus measurements for all runs.

\begin{tabular}{lcccccc}
\hline Secondary circuit & EXP.RUN-1 & CALC.RUN-1 & EXP.RUN-2 & CALC.RUN-2 & EXP.RUN-3 & CALC.RUN-3 \\
\hline Pressure SG-1 and SG-3 (bar) & $24-24.7$ & 24 & $31-32$ & 32 & $31-32$ & 32 \\
Pressure SG-2 and SG-4 (bar) & 21 & 21 & 20 & 21 & 20 & 21 \\
Water level in SG-1 and SG-3 (m) & 0 & 0 & 0 & 0 & 0 & 0 \\
Water level in SG-2 and SG-4 (m) & 12.1 & 12.1 & 12.1 & 12.1 & 12.1 & 47 \\
Feedwater temperature $\left({ }^{\circ} \mathrm{C}\right)$ & 50 & 50 & 47 & 47 & 47 \\
\hline
\end{tabular}

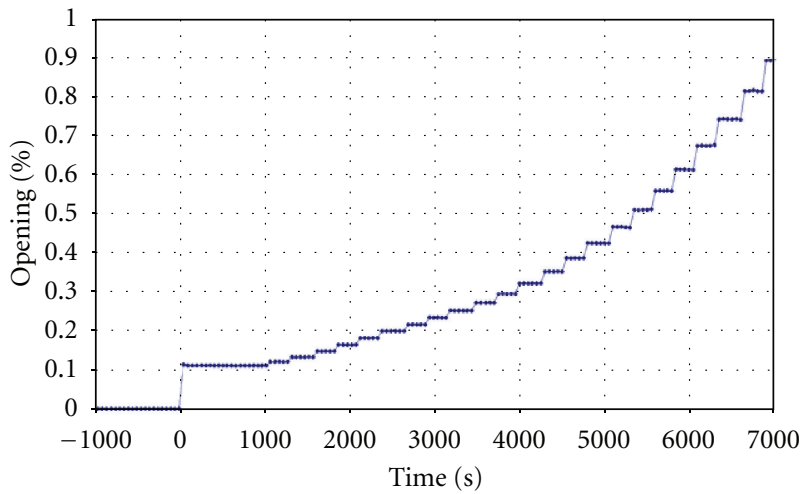

Figure 8: Run-1: Calculated atmospheric discharge valve opening evolution in the active SG.

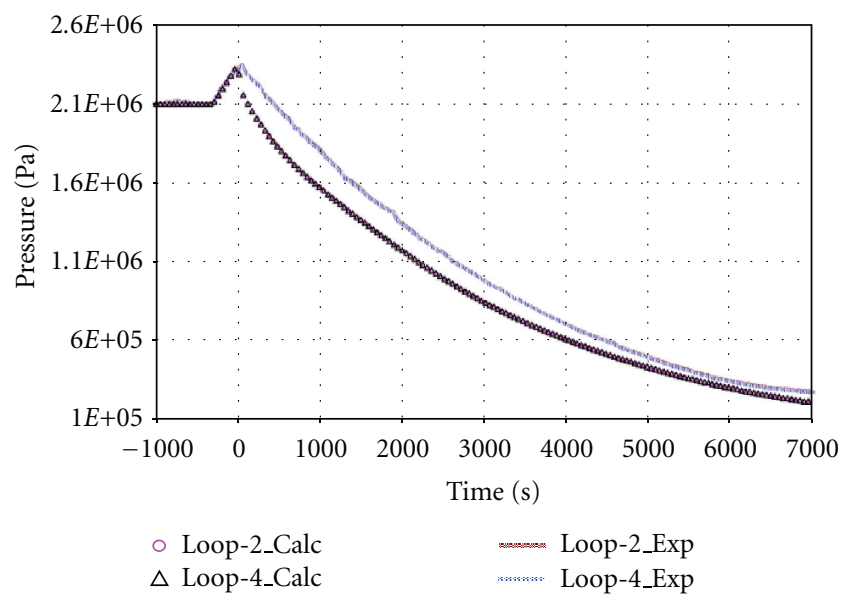

FIgURE 9: Run-1: Secondary side pressure evolution in the active loops.

the middle tube (Tube-19), then in the longest tube (Tube29), and finally in the shortest tube (Tube-1). While for loop-3 (see Figure 10(b)), the flow stops first in the longest tube (Tube-29), then in the shortest tube (Tube-2) and later in the middle tube (Tube-19). This behaviour is obviously governed by the void growth, the temperature and flow redistribution in the $\mathrm{U}$-tubes.

This trend is also observed in the CATHARE predictions (see Figure 11), where the flow is interrupted first in the middle length tube, then in the longest tube, and finally, in the shortest tube.
5.2. G2.1 Run-2. The second run is more or less identical to the first one, except for the fact that the primary pressure is kept high enough to preclude any void formation in the U-tubes. Unlike the case in Run-1, the NCI is the result of the driving force balance in the different loops of the tests facility. The test starts by the isolation of the secondary side of the active SG from the steam header. The cooldown via the corresponding ADV is activated immediately at the end of the conditioning phase; there is no heat-up period in this run.

At the beginning of the cooldown phase, as can be seen in Figure 12, the calculated hot leg temperature in the active loops is overpredicted by $2.0^{\circ} \mathrm{C}$. This difference was already observed in Run-1 case. On the other hand, unlike the first run, the coolant flow in all loops is well predicted (see Figure 13); the final state of the conditioning phase of Run-2 is well simulated.

Throughout the cooldown phase, the calculated coolant temperatures (see Figure 12), the flow rate evolutions (see Figure 14), and the secondary pressure decrease (see Figure 13), in the active loop-2 and loop-4, match well the experimental trends. As it was the case for Run-1, the agreement is less good in the inactive loop-1 and loop-3. Indeed, there are differences between the measured flow rates in loop-1 and loop-3. This leads to a flow interruption in loop-1, and a flow restart in loop-3 at around 5500 s. This flow restart, as can be seen in Figure 12, is most probably due to the fact that at the end of the test (beyond $5000 \mathrm{~s}$ ) the cooldown rate of $50^{\circ} \mathrm{C} / \mathrm{h}$ can no longer be ensured. Its mean value, after $5000 \mathrm{~s}$, is less than $25^{\circ} \mathrm{C} / \mathrm{h}$.

In the CATHARE model, the flow interrupts in both loops at the same time as a consequence of the driving forces balances in loop- 1 and loop-3 and the driving force in the vessel. The code predicts an NCI time that corresponds with the experimental NCI observed in loop-1.

5.3. G2.1 Run-3. During the third run, a stepwise cooldown procedure is performed. As in Run-2, the primary pressure is kept high enough to preclude any void formation in the U-tubes. In the first step, the active loops temperature is decreased by $20^{\circ} \mathrm{C}$ following a linear cooldown rate of $50^{\circ} \mathrm{C} / \mathrm{h}$. After a stabilization period of $1800 \mathrm{~s}$, the active loop temperature is reduced by $30^{\circ} \mathrm{C}$ according to a cooldown rate of $50^{\circ} \mathrm{C} / \mathrm{h}$. Then, after stabilization period of $2260 \mathrm{~s}$, the third and last step is initiated. The temperature is decreased by $40^{\circ} \mathrm{C}$ during $7120 \mathrm{~s}$ instead of $2880 \mathrm{~s}$. Indeed, during this step the cooldown rate of $50^{\circ} \mathrm{C} / \mathrm{h}$ could not be reached at the end 


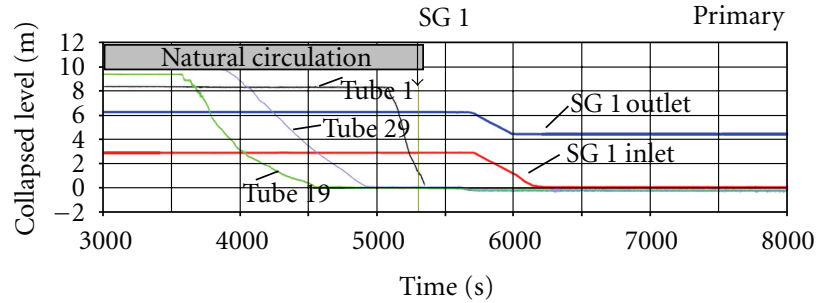

(a)

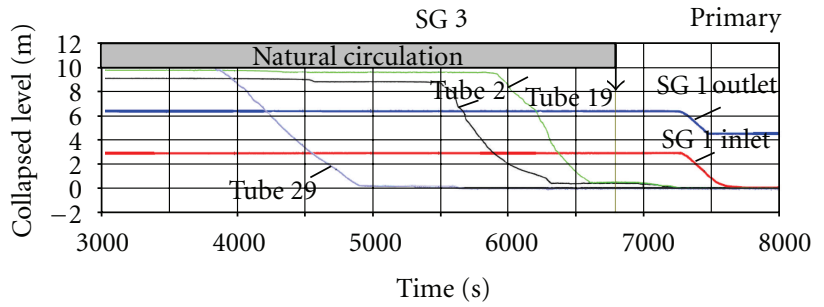

(b)

FIGURE 10: (a) Run-1: Measured collapsed levels in the U-tubes of the inactive loop-1. (b) Run-1: Measured collapsed levels in the U-tubes of the inactive loop-3.

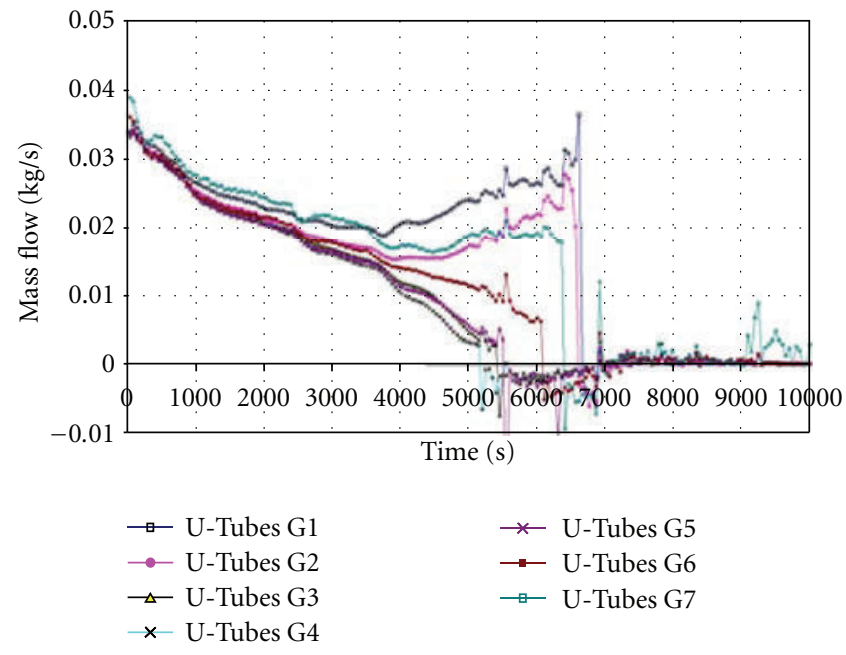

FIGURE 11: Run-1: Predicted mass flow rate evolution in the U-tubes of the inactive loops.

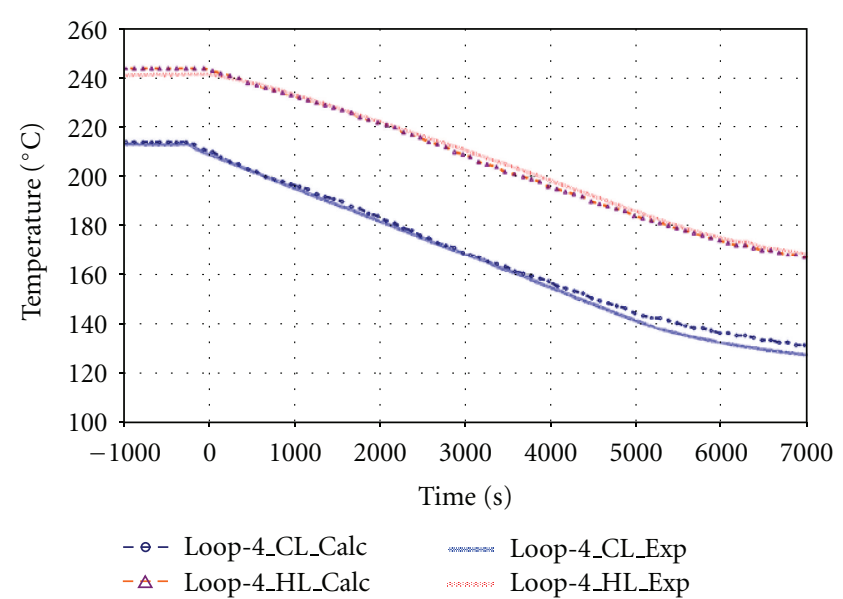

FIGURE 12: Run-2: Cold and hot leg temperature evolution in the active loops.

of the test due to the fact that the secondary side pressure is almost at atmospheric levels.

As shown in Figure 15, the calculated cold and hot-leg temperatures in the active loops are well predicted. The coolant flow in all loops is also well predicted (see Figure 16).

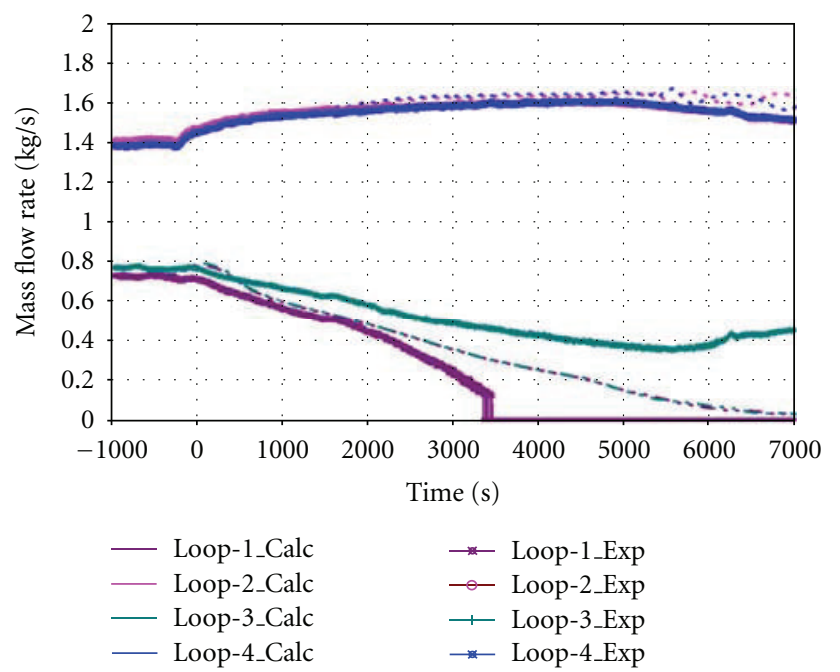

Figure 13: Run-2: Loops flow rate evolutions.

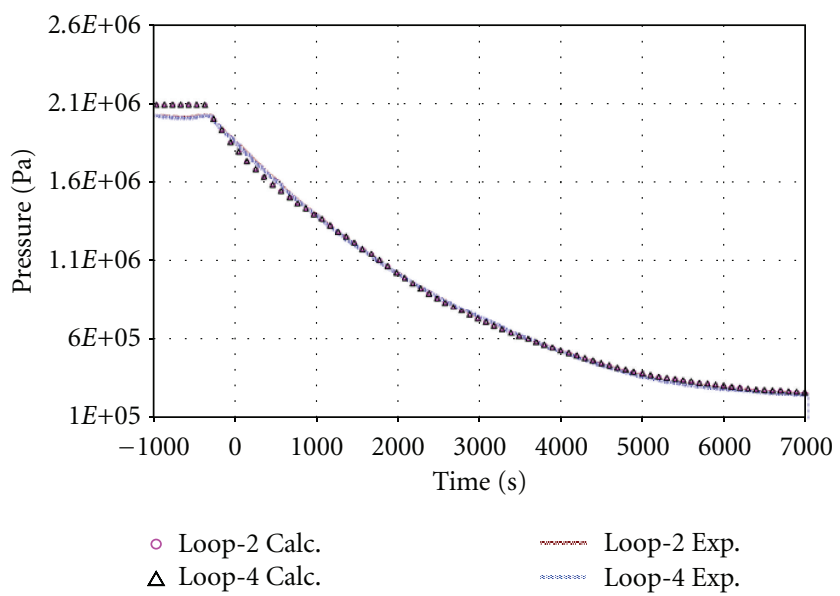

FIGURE 14: Run-2: Secondary side pressure evolution in the active loops.

This trend is kept throughout the entire test time span. The secondary pressure decrease is also well predicted by the calculation (see Figure 17). As it is the case for the former runs, the agreement between the calculated and measured mass flow rate in the inactive loops is less good. This is mainly 


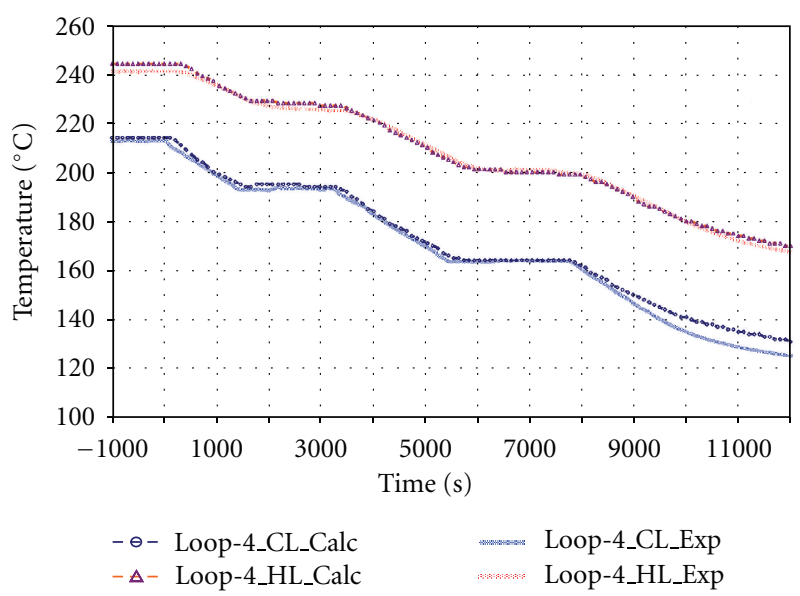

Figure 15: Run-3: Cold and hot leg temperature evolution in the active loops.

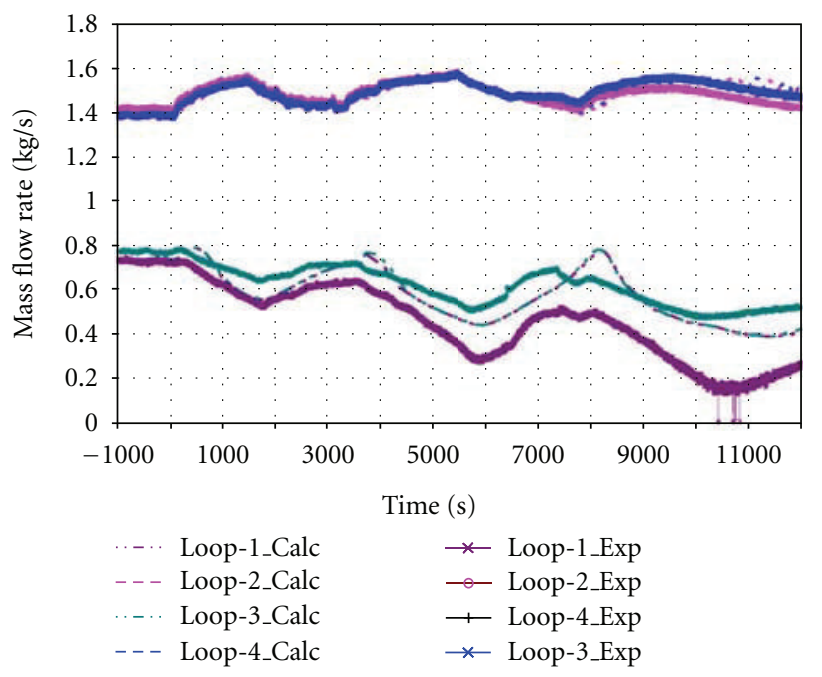

Figure 16: Run-3: Loops flow rate evolutions.

due to the differences in the measured flow rates that exist between loop-1 and loop-3. This difference is most probably due to geometric differences between loop-1 and loop-3, and also to some mixing effect in the upper part of the downcomer that are not modelled in the CATHARE model. However, the predicted values lie between the measured mass flow rates in loop-1 and loop-3.

Unlike Run-1 and Run-2, no flow interruption in the inactive loops is observed experimentally for Run-3. The flow rate in these loops decrease with decreasing temperatures of the active loops. In loop-1, the flow rate reaches $15 \%$ of its initial value during the third cooldown step. However, as already mentioned above, the cooldown rate of $50^{\circ} \mathrm{C} / \mathrm{h}$ during the third step was not ensured; the mean cooldown rate during the last step is around $36^{\circ} \mathrm{C} / \mathrm{h}$. Therefore, if during this period the cooldown rate of $50^{\circ} \mathrm{C} / \mathrm{h}$ would have been ensured, the flow rate in loop-1 would probably have been interrupted. Furthermore, if shorter periods

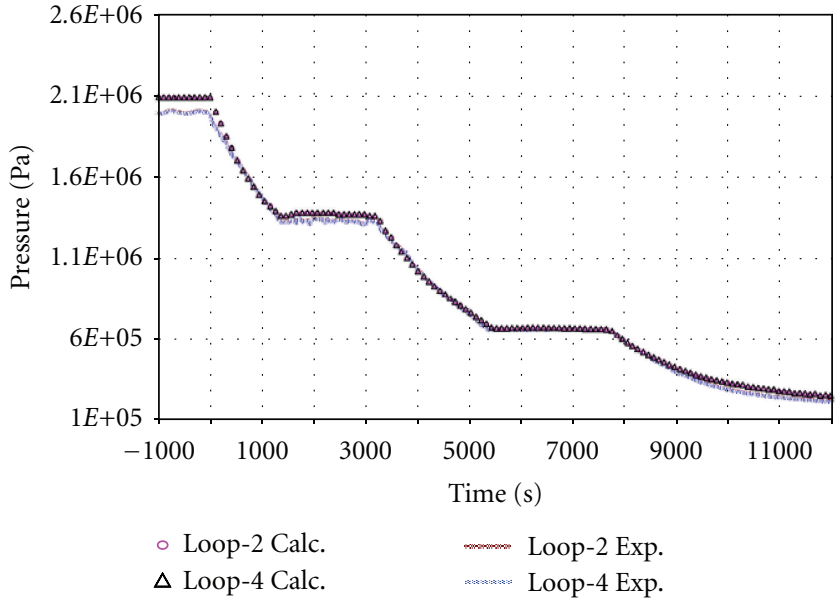

FIgURE 17: Run-3: Secondary side pressure evolution in the active loops.

between the temperatures decrease of the stepwise cooldown procedure were considered, NCI would also occur.

\section{Conclusions}

In the current study, asymmetric cooldown tests with empty and isolated SGs in the 4-loop PKL facility are investigated. The impacts of several cooldown strategies on the NCI occurrence are assessed experimentally and simulated numerically with the CATHARE code. According to the calculation results, it can be concluded that:

(i) NCI occurs when high linear value of the cooldown rate (i.e., $50^{\circ} \mathrm{C} / \mathrm{h}$ ) is performed. The NCI occurs in Run-1 and Run-2 due to steam formation in the apex of the U-tubes, and due to driving forces balance in the loops, respectively;

(ii) a stepwise cooldown procedure allows avoiding NCI, as far as the temperature steps are rigorously chosen in relation to the decay heat level and the time interval between successive cooldown steps;

(iii) the experiments show that slight configuration differences between inactive loops could have an important impact on the NCI occurrence;

(iv) the CATHARE computer code can accurately simulate the NCI phenomenon. However, deeper investigation and assessment of broader conditions could impact the NCI occurrence, as the power level, the cooldown rate and strategy, and the 3D mixing effect in the vessel downcomer.

\section{Nomenclature}
$\Delta P_{f}:$ Friction pressure drop $\left(\mathrm{N} / \mathrm{m}^{2}\right)$
$\rho: \quad$ Density of the fluid $\left(\mathrm{kg} / \mathrm{m}^{3}\right)$
G: Acceleration due to gravity $\left(9.81 \mathrm{~m} / \mathrm{s}^{2}\right)$
$z$ : $\quad$ Vertical coordinate $(\mathrm{m})$. 


\section{Acronyms}

ADV: Atmospheric discharge valve

NC(I): Natural circulation (interruption)

NPP: Nuclear power plant

PRZ: Pressurizer

PWR: Pressurized water reactor

RCS: Reactor coolant system

RHRS: Residual heat removal system

SG: Steam generator.

\section{Acknowledgments}

The authors would like to express their thanks to the entire PKL-2 group and more particularly to Dr. K. Umminger.

\section{References}

[1] J. Vlassenbroeck, A. B. Salah, and A. Bucalossi, "Assessment of natural circulation interruption during asymmetric cooldown transients," Nuclear Technology, vol. 172, no. 2, pp. 179-188, 2010.

[2] K. Umminger, W. Kastner, J. Liebert, and T. Mull, "Thermal hydraulics of PWRS with respect to boron dilution phenomena. Experimental results from the test facilities PKL and UPTF," Nuclear Engineering and Design, vol. 204, no. 1-3, pp. 191-203, 2001.

[3] http://www.oecd-nea.org/jointproj/pkl.html.

[4] K. D. Dubiel and R. M. Mandl, "Abfahren eines DWR ohne Hauptkühlmittelpumpen nach Dampferzeuger-Heizrohrbruch mit Erreichen der Notkühlkriterien," Private Communication, 1994.

[5] Equipe CATHARE, DRN/DTP/SMTH/LMDS, "CATHARE2 V2.5_1/mod8.1 Dictionary," SMTH/LMDS/EM/2002_067, 2008.

[6] R. Guneysu and H. Kremin, "Description of the PKL Test Facility," NTCTP-G/2007/en/0010, 2007.

[7] S. P. Schollenberger and K. Umminger, "Determination of Pressure Losses in the PKL III test Facility for Mass Flows of 0.8 to $25.0 \mathrm{Kg} / \mathrm{s}$ per Loop," NTT1-G/2006/en/0066, 2006.

[8] S. P. Schollenberger and T. Mull, "Determination of Heat Losses in the PKL III Test Facility for Temperature Levels from 25 to 250 ${ }^{\circ}$ C, NTT1-G/2006/en/0067, 2006.

[9] R. Guneysu and H. Kremin, "Determination of Individual Volumes and of Total Volume in the PKL Test Facility," NTCTPG/2007/en/0011, 2007. 

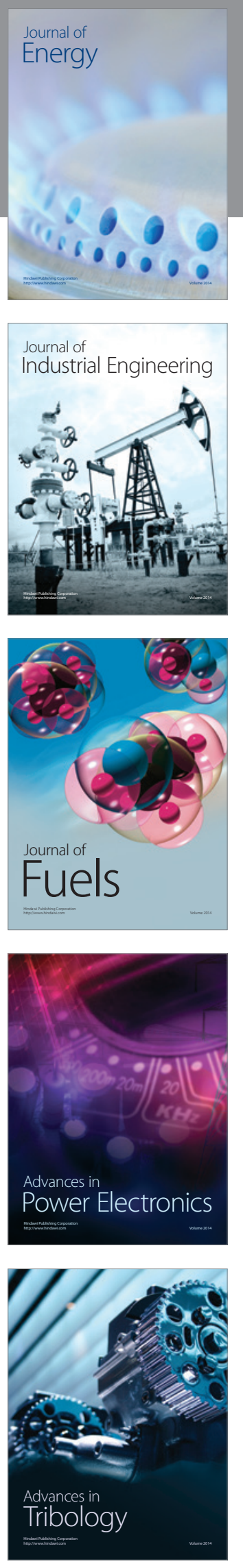
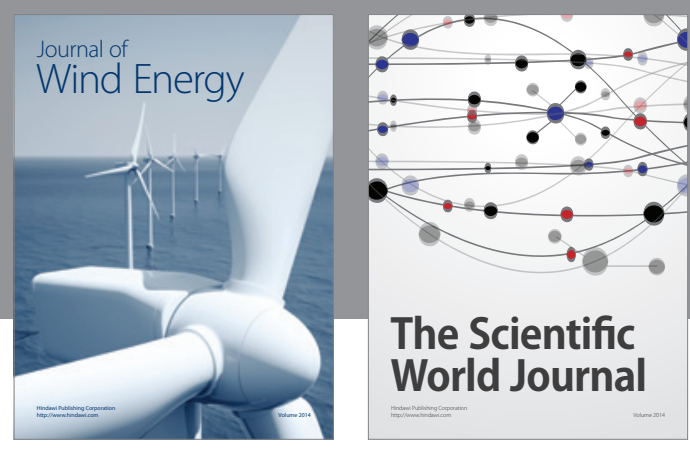

The Scientific World Journal

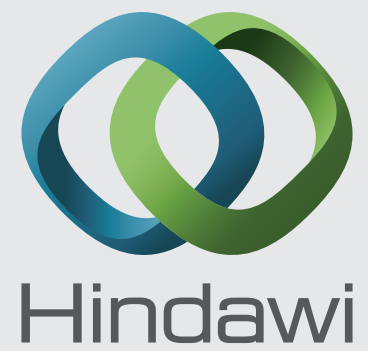

Submit your manuscripts at http://www.hindawi.com
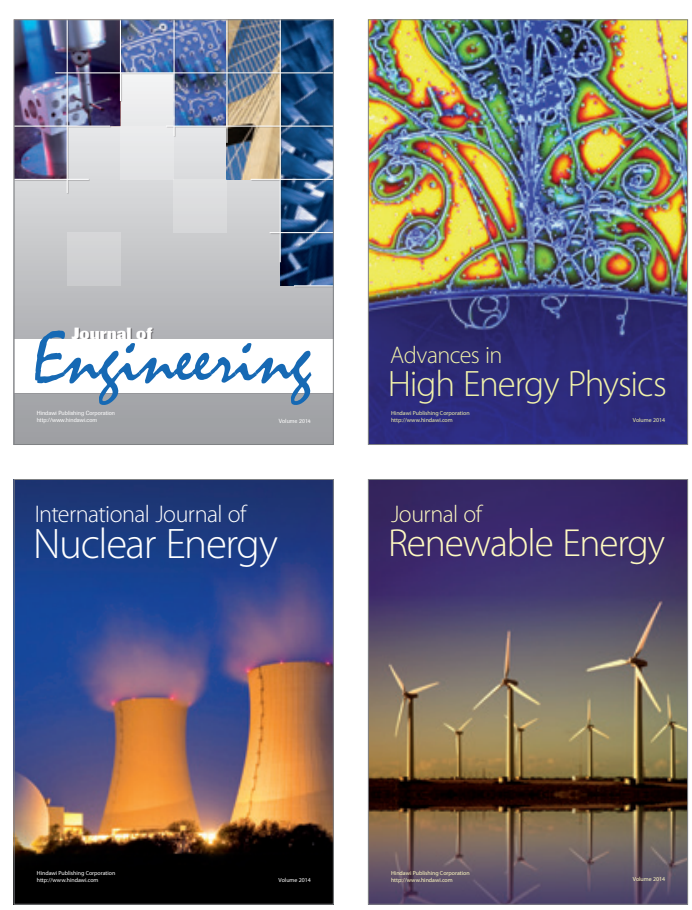

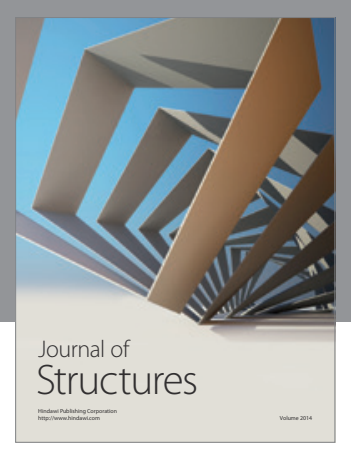

Rotating
Mechinery
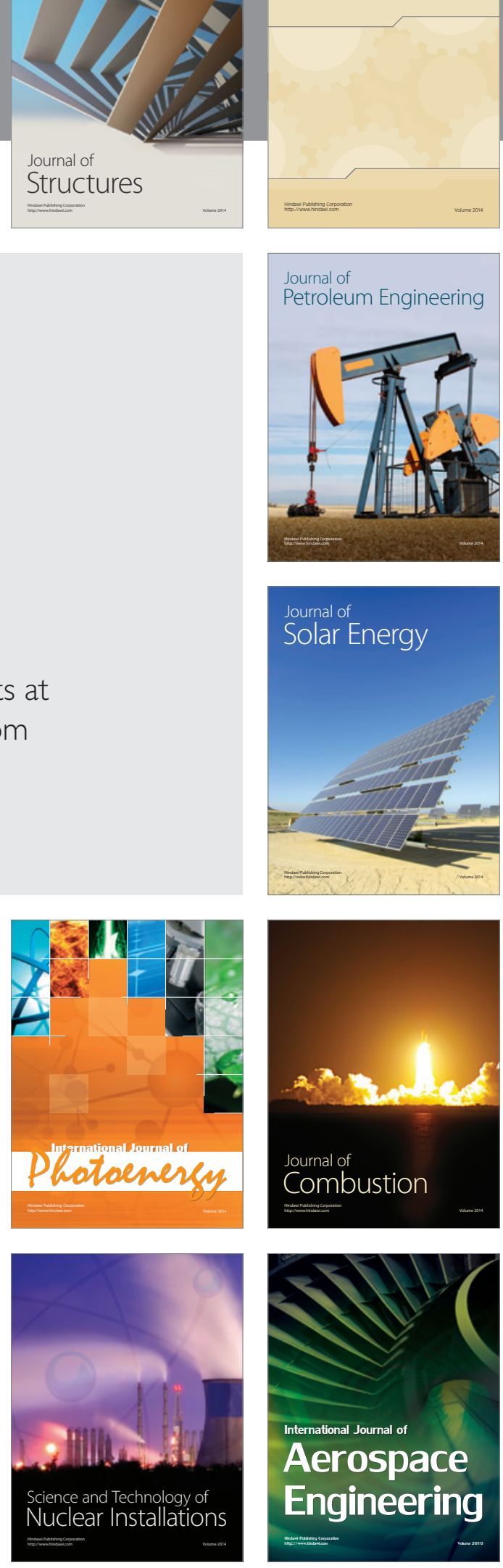